\title{
BELIEVE IT OR NOT: HOW SOCIAL AXIOMS IMPACT ON CUSTOMER PERCEPTIONS OF CORPORATE BRAND REPUTATION
}

\author{
Kevin Money, University of Reading, U.K. \\ Bettina West, Ryerson University, Canada \\ Carola Hillenbrand, University of Reading, U.K.
}

\begin{abstract}
The importance of corporate brand reputation has, in recent years, been recognised by scholars and practitioners alike (Brammer \& Pavelin, 2006; Deephouse \& Carter, 2005; Fombrun \& Van Riel, 2004). A positive reputation can create competitive advantage and superior brand performance, thereby placing the management of this intangible resource in line with operational, legal and financial duties of managers (Carter, 2006; Gardberg \& Fombrun, 2006; Jones et al., 2000; Ravasi \& Schultz, 2006; Walsh et al., 2009). However, despite its widely acknowledged importance, and despite the fact that customers are a vital stakeholder group, there has been little systematic research investigating corporate brand reputation through the lens of customers, let alone individual differences among customers.
\end{abstract}

In this article we examine the moderating impact of deeply-held individual beliefs, known as social axioms, on the development of corporate brand reputation from a customer perspective. Building on a conceptual model derived from literature, we investigate two dimensions of importance to customers - reputation for product/service quality and reputation for social responsibility (Gardberg \& Fombrun, 2006; McWilliams et al., 2006; Sen \& Bhattacharya, 2001). We link them to antecedents associated with customer experiences as well as to outcomes related to customer attitudes and behaviour intentions (Hillenbrand, 2011; Walsh et al. 2009). We also build on theoretical advances in the study of individual differences and social axioms (Kwantes \& Karam, 2009; Leung et al., 2002; Zhou et al., 2009), to examine individual axiomatic beliefs about the world as moderators of perceptions and outcomes of corporate brand reputation. We test the impact of two dimensions found within Leung et al.'s (2002) social axioms construct, identified as social cynicism and religiosity, on several driver and outcome variables.

Data were collected in the form of a self-complete questionnaire from 216 customers of an established Canadian retailer in the fall of 2009. The component based approach PLS-SEM was utilised to examine the relationships among the study constructs due to the existence of both reflective and formative indicators (Chin, 1998). We then tested for moderating influences according to a procedure developed by Henseler and Fassot (2009), and found significant differences in several model paths between individuals identified as either high or low on social cynicism and religiosity.

Our findings revealed individuals low on social cynicism are more likely than high cynics to attribute brand reputation for product/service quality to their direct personal interactions with a firm and rely less on what they see/hear from other sources. In addition, brand reputation for social responsibility is more helpful in reducing distrust with these 'low cynicism' customers. Finally, customers who have strong religious beliefs tend to be less likely to be influenced by 'others-related' experiences when forming perceptions of brand social responsibility, and are less likely than their low religious counterparts to increase trust in a brand based on its perceived product/service quality.

At a time when firms grapple with how best to manage customer relationships, our model provides a fresh approach for understanding how customers perceive and respond to corporate brand reputation based on their individual axiomatic beliefs.

References available upon request. 